\title{
UNA VISITA A LA OBRA DE CABALLERO DESDE LA FENOMENOLOGÍA ${ }^{1}$
}

\author{
Oscar Javier Sandoval Rodríguez²
}

\author{
A VISIT TO CABALLERO'S WORK THROUGH PHENOMENOLOGY \\ UMA VISITA À OBRA DE CABALLEROA PARTIR DA FENOMENOLOGIA
}

Fecha de recepción: 17 de agosto del 2020

Fecha de aceptación: 15 de enero del 2021

Disponible en línea: 12 de abril del 2021

Sugerencia de citación: Sandoval Rodríguez, O. J. (2021). Una visita a la obra de Caballero desde la fenomenología. Razón Crítica, (11), 231-252. https://doi.org/10.21789/25007807.1735

(1) El presente artículo sintetiza el proyecto de grado "La experiencia interpretativa frente a la obra de Luis Caballero desde la fenomenología”, presentado para obtener el título de magíster en Estética e Historia del Arte de la Universidad de Bogotá Jorge Tadeo Lozano.

(2) Magíster en Estética e Historia del Arte de la Universidad de Bogotá JorgeTadeo Lozano Profesor de la Corporación Universitaria Unitec, Colombia

oscarj.sandovalr@utadeo.edu.co | https://orcid.org/0000-0002-6929-2254 


\section{R E S U M E N}

La búsqueda de imagen necesaria fue el concepto con que Luis Caballero definió su obra a finales de los 70, desarrollando un tratamiento artístico que inducía una interpretación ambigua de las emociones que podrían experimentar los cuerpos dibujados. Este tratamiento artístico se manifestaba en los recursos pictóricos con que representaba los gestos corporales. Suponiendo que la ambigüedad es una característica que se da en el entendimiento de algo, proponer que en los gestos corporales de la obra de Caballero hay ambigüedad es admitir que esta hace parte de la interpretación de un observador sobre una obra, es decir, los gestos no son ambiguos, lo ambiguo es el entendimiento que sobre ellos ha de tener un observador. El proyecto investigativo en consecuencia se propuso revisitar la obra de Caballero desde la experiencia interpretativa de quien observa, para lo cual fue pertinente abordar la relación espectador/pintura como un evento fenomenológico, esto es, revisar las relaciones que un sujeto entabla con un objeto estético sobre el cual, en la experiencia, se relaciona y puede ser consciente de tres instancias manifestadas: el objeto material (bilk), unos objetos representados (bilksujet) y los aspectos constitutivos de representación (bildobjekt).

PALABRAS CLAVE: Experiencia interpretativa; Luis Caballero; fenomenología; gesto corporal; cuerpo fragmentado. 


\section{A B S T R A C T}

The search for the required image was the concept adopted by Luis Caballero to define his work at the end of the 70s, developing an artistic treatment that fostered an ambiguous interpretation of the emotions that drawn bodies could experience. This artistic treatment is manifested in the pictorial resources used by this artist to represent bodily gestures. Assuming that ambiguity is a characteristic that occurs in the understanding of something, the fact of proposing the existence of ambiguity in the corporal gestures of Caballero's work is to admit that such ambiguity is part of an observer's interpretation, that is, gestures are not ambiguous, but rather the understanding of an observer about them. Consequently, this research project tried to revisit Caballero's work from the interpretive experience of the observer, making it necessary to address the relationship observer/painting as a phenomenological event, that is, reviewing the relationships that an individual establishes with an aesthetic object with which, in real life, he/she becomes related and could be aware of three manifested instances: the material object (bilk), some represented objects (bilksujet), and the constitutive aspects around representation (bildobjekt).

Keywords: Interpretive experience; Luis Caballero; phenomenology; body gesture; fragmented body.

\section{R E S U M O}

A procura pela imagem necessária foi o conceito com o qual Luis Caballero definiu sua obra no final dos 1970, desenvolvendo um tratamento artístico que induzia uma interpretação ambígua das emoções que os corpos desenhados poderiam experimentar. Esse tratamento artístico era manifestado nos recursos pictóricos com os quais representava os gestos corporais. Ao supor que a ambiguidade seja uma característica dada no entendimento de algo, propor que haja ambiguidade nos gestos corporais da obra de Caballero é admitir que esta faz parte da interpretação de um observador sobre uma obra, isto é, os gestos não são ambíguos; o ambíguo é o entendimento que um observador deve ter sobre eles. Nesse sentido, o projeto de pesquisa se propôs a revisitar a obra de Caballero a partir da experiência interpretativa de quem observa; para isso, foi pertinente abordar a relação espectadorpintura como um evento fenomenológico, ou seja, revisar as relações que um sujeito estabelece com um objeto estético sobre o qual, na experiência, se relaciona e pode ser consciente de três instâncias manifestadas: o objeto material (bilk), objetos representados (bilksujet) e os aspectos constitutivos de representação (bildobjekt).

\section{PALAVRAS-CHAVE: experiência interpretativa; Luis Caballero; fenomenologia; gesto corporal; corpo fragmentado.}




\section{N T R O D U C C I Ó N}

A 25 años del fallecimiento de Luis Caballero, su obra se mantiene y revitaliza con los constantes diálogos que suscita en cada nueva generación de observadores. En su recordado comentario para la exposición de 1990 en la Galería Garcés Velásquez de Bogotá3 mostrababa dos aspectos que esbozarían las pretensiones con que abordó su obra y que a la postre la mantienen vigente: "Hay que intentar hacer una gran obra. En general el arte contemporáneo peca por falta de ambición. En plástica hacer una gran obra es crear una imagen necesaria: lo demás es decoración” (Caballero, 1990). La definición de gran obra para Caballero surge en oposición al arte contemporáneo que exploró en su etapa de formación en París ${ }^{4}$ y transitó durante los años 60 y principios de los $70^{[5]}$. En cuanto su interés siempre fue el cuerpo humano, su exploración inicial fue esquemática, expresiva y abstracta (Malagón-Kurska, 2012, p. 7). Al parecer no le ofrecía el carácter trascendental que requería su gran obra, una obra que no fuera efímera acorde al ismo del momento, ni se agotara en un único encuentro con el observador.

El cuerpo humano le interesaba porque con este podía comunicar sus inquietudes ${ }^{6}$, que, a la vez, son ansiedades que comparte con los

\footnotetext{
3 Actualmente Espacio Alonso Garcés y Reinaldo Annicchiarico.

4 La Académie de La Grande Chaumiére, 1963.

5 La obra de Caballero entre el 63 y el 66 estará fuertemente influenciada por el pop art europeo y el Modernismo de Bacon (Sandoval, 2020, p. 19).

6 "Me parece más interesante hablar en función de una imagen finalizada de un cuadro mío. ¿Por qué a través de la imagen de un hombre muerto siento que puedo comunicar más cosas que a través de la imagen de un florero?" (Caballero \& Hernández, 1986, p. 33). "Desde que empecé a pintar seriamente yo solo he pintado el cuerpo humano por ser este el único tema que me apasiona
} 
espectadores que ven su obra: la naturaleza humana despojada de la materialidad y banalidad del mundo, y expuesta en su más pura esencia, el cuerpo desnudo en su condición extrema del sentir y la emoción ${ }^{7}$, las relaciones con el otro en un estado primigenio sin mediación de convenciones sociales. En esa manera de representar el cuerpo humano su obra se ha mantenido vigente, sencillamente porque lo que ve el espectador tiene que ver consigo mismo, con una naturaleza que usualmente evitamos y ocultamos, no solo en términos de la desnudez, sino del experimentar. Ante situaciones extremas y al límite, como el acto sexual o el dolor ante la muerte, el individuo vuelve a su estado esencial.

Para que estos temas, siempre vigentes, realmente cuestionaran al observador sin que se agotaran en una simple mirada, Caballero tenía que lograr que sus cuerpos se hicieran reales y sintieran ante los ojos del espectador. La gran obra de Caballero se materializaría en la realización de una imagen necesaria, en la que el dibujo del cuerpo humano por virtud propia se hiciera sagrada ${ }^{8}$. El concepto de la imagen necesaria fue motivo de estudio para la investigadora Margarita Malagón-Kurska, quien propondría "[...] es la imagen del cuerpo en sus gestos ambiguos, la que para Caballero es necesaria y sagrada al mismo tiempo" (MalagónKurska, 2000, p. 93). En este sentido, el tratamiento artístico en la obra de Caballero hacia la década de $\operatorname{los} 80^{[9]}$ enfatizará en la ambigüedad

de verdad, y a través del cual me siento capaz de expresar cualquier cosa" (Marta Traba, citada en Malagón-Kurska, 2012, p. 15).

7 "Yo no soy el primero en ver el cuerpo humano — reconoce Caballero con su habitual modestia-, ni el primero al que conmueve la relación entre dos seres. Todas las relaciones que pueden existir entre ellos: repulsión, unión, odio o éxtasis. No son temas nuevos, pero son problemas siempre nuevos y nunca resueltos, que cada hombre debe despejar y no pueden ser aprendidos" (Caballero \& Hernández, 1986, p. 13).

8 Confróntese (Bayón, 1990). El interés de la imagen sagrada en Caballero está vinculado a su atracción hacia las imágenes religiosas cristianas tanto por la iconografía del cuerpo como por su significado. Con respecto a esto último, una imagen religiosa es sagrada en virtud del personaje al que remite (Rubiano, 2014). La pretensión de Caballero es que sus imágenes fueran sagradas por virtud propia en cuanto conmocionarían al observador, es decir, el cuerpo se sacraliza ante los ojos de quien lo observa, interpretando que este experimenta sensaciones extremas y al límite del umbral vida/muerte. "Yo lo que quisiera es poder llegar a crear una imagen cargada de sentido como un cuadro religioso: como un ícono, una imagen sagrada. Crear imágenes de cuerpos en carne viva. Crear imágenes en las que los valores emotivos, sensuales y espirituales nos hagan olvidar que se trata de un simple cuadro" (Bayón, 1990).

9 El desarrollo y evolución de la obra de Luis Caballero suele abordarse en tres etapas: primero, una "esquemática, expresiva y abstracta" (Malagón-Kurska, 2012, p. 7), que va desde 1961 a inicios de los 70, y que se considera como una búsqueda de influencias (Valencia-Herrera, 2015). La segunda etapa abarcaría la década de los 70 evidenciándose un "pliegue al barroco" (ValenciaHerrera, 2015) con una obra de carácter más clásico y naturista. La tercera etapa, que se extiende desde inicios de los 80 hasta 1992 (cuando deja de pintar por problemas de salud que lo llevarán a la muerte en 1995), muestra una obra "[...] expresionista, un cierto regreso a lo abstracto" (Malagón-Kurska, 2012, p. 7). En esta etapa se desarrolla una "estética mínima” (Valencia-Herrera, 2015) tendiente a producir la ambigüedad que hará posible el proyecto de la imagen necesaria. 
como mecanismo para activar diálogos entre el espectador y la obra: “[...] me interesa la ambigüedad precisamente por las diferentes lecturas que permiten el mismo cuadro. El placer y el dolor, la unión y la lucha tienen la misma imagen y el mismo gesto" (Bayón, 1990).

Acogiendo la interpretación de la Real Academia de la Lengua del concepto ambigüedad, según el cual, “[...] puede entenderse de varios modos o admitir distintas interpretaciones y" dar, por consiguiente, motivo a dudas, incertidumbre o confusión", se hace pertinente considerar el papel primordial del observador frente a la obra de Caballero, para que en su interpretación se dé la ambigüedad pretendida por el pintor; ambigüedad que, si bien admite posibles interpretaciones, ha de estar dentro las intenciones del artista. ¿Cómo se podría describir la experiencia interpretativa frente al tratamiento artístico que Caballero dio a su obra, para que provocara la ambigüedad pretendida en el observador? Esta cuestión guía la reflexión del presente artículo.

\section{¿QUÉ ES LO AMBIGUO DE LA OBRA DE LUIS CABALLERO?}

Un primer acercamiento sobre lo ambiguo de la obra del pintor colombiano nos lo ofrece Margarita Malagón-Kurska, quien propone que esto se da en el gesto facial y el gesto corporal (2000, p. 7).

Adicionalmente, la investigadora propone que, a la luz de lo que podrían experimentar los cuerpos, la ambigüedad se da en el gesto de lo que experimentan, esto es, el gesto del cuerpo puede ser un gesto erótico, místico o violento (2000, p. 92). Teniendo en cuenta que la descripción pretendida por este artículo surge de acoger la ambigüedad como una característica interpretativa, se hace pertinente puntualizar dos aspectos en la interesante aproximación que ofrece Malagón-Kurska. En primer lugar, un gesto, en cuanto es una disposición corporal ${ }^{10}$, se da con relación a un estado emocional, es decir, los gestos, al ser índices de emociones, son intencionales, siendo evidencias del sentir de un sujeto a través de su

\footnotetext{
10 "Más que lo antedicho - y esto es lo curioso— son los movimientos inútiles del otro, los que no sirve a finalidad aparente alguna, a saber, sus gestos, quienes nos revelan más de él. El otro hombre nos aparece sobre todo en su gesticulación y con no escaso fundamento podemos decir que un hombre es sus gestos" (Ortega \& Gasset, citado por Malagón, 2000, p. 58). La definición del gesto para la Real Academia de la Lengua es "Movimiento del rostro, de las manos o de otras partes del cuerpo, con que se expresan afectos o se transmiten mensajes” (Real Academia Española, s.f.).
} 
cuerpo. Segundo, Caballero implementó un tratamiento artístico tanto a los cuerpos como a sus disposiciones, posibilitando que un observador, en su interpretación, asignara emociones a dichas disposiciones; de hecho, en tal asignación de emociones emerge la ambigüedad. Sobre lo que se quiere llamar la atención acerca del abordaje del gesto es su carácter transversal al fenómeno interpretativo en cuanto este se manifiesta en la imagen a través de la disposición de los cuerpos, lo que la hace adquirir un significado emocional asignado por el espectador.

Figura 1. El carácter transversal del gesto en el proceso interpretativo

\begin{tabular}{|l|r|r|}
\hline \multicolumn{2}{|c|}{ PERCEPCIÓN } & ESPECTADOR \\
\cline { 2 - 3 } & $\begin{array}{c}\text { Presentación } \\
\text { del cuerpo }\end{array}$ & $\begin{array}{c}\text { Reconocimiento } \\
\text { del cuerpo }\end{array}$ \\
\hline $\begin{array}{c}\text { GESTO } \\
\text { disposición del } \\
\text { cuerpo/rostro }\end{array}$ & $\begin{array}{c}\text { GESTO } \\
\text { intencionalidad (representación } \\
\text { de una emoción) }\end{array}$ \\
\hline & & $\begin{array}{c}\text { Asociación a lo que puede estar } \\
\text { experimentando el cuerpo observado. }\end{array}$ \\
\hline
\end{tabular}

Fuente: Sandoval (2020).

Ahora bien, suponiendo que la ambigüedad es una característica interpretativa que se da gracias al tratamiento artístico implementado por Caballero, el paso que se debe seguir es determinar cómo se manifiestan dichos recursos en los tratamientos que el pintor hizo tanto de los aspectos figurativos como en sus decisiones plásticas. Con relación al aspecto referencial, es decir, a la identificación de cuerpos, el observador no solo se enfrenta a la interpretación de las disposiciones corporales que ve, sino a las que se ausentan por la implementación del recurso de la fragmentación corporal $^{11}$, teniendo en cuenta que dicha fragmentación sugiere la omisión de la información visual y no una ausencia física de las partes omitidas, ya que no hay índices de amputaciones o cortes de las partes. Acorde con lo anterior, es pertinente llamar la atención sobre la reiterada omisión

11 Martha Ramírez (2014) hace una reflexión sobre el cuerpo fragmentado en el arte del s. xx. A su vez, cita a Calabrese en la acotación dialéctica entre la idea del todo, que posibilita la idea de la parte, el fragmento: "El uno no se define sin el otro, los dos mantienen relaciones de reciprocidad, implicación y presuposición” (Ramírez, 2014, p. 116). 
de rostros y cabezas en la etapa expresionista de los 80 de Caballero ${ }^{12}$. La repercusión que esto tendrá más adelante en la descripción de la experiencia interpretativa es que el gesto del rostro, que podría ser más preciso para la determinación de una emoción, se asume con relación al gesto del cuerpo visible.

Tabla 1. Relación del tratamiento de los recursos pictóricos con relación a las interpretaciones que pueden generar

\begin{tabular}{|l|c|c|c|c|}
\hline \multicolumn{2}{|c|}{ RECURSOS PICTÓRICOS DE LA OBRA } & \multicolumn{2}{c|}{$\begin{array}{c}\text { POSIBILIDADES } \\
\text { INTERPRETATIVAS }\end{array}$} \\
\hline \multirow{2}{*}{$\begin{array}{l}\text { Tratamiento } \\
\text { artístico } \\
\text { referencial }\end{array}$} & $\begin{array}{c}\text { Presentación del } \\
\text { cuerpo (torso- } \\
\text { extramidades) }\end{array}$ & $\begin{array}{c}\text { Fragmentación del } \\
\text { cuerpo }\end{array}$ & $\begin{array}{c}\text { Ambigüedad del } \\
\text { gesto corporal }\end{array}$ & $\begin{array}{c}\text { Gesto erótico } \\
\text { Gesto místico }\end{array}$ \\
\cline { 2 - 3 } & $\begin{array}{c}\text { Presentación } \\
\text { del rostro }\end{array}$ & $\begin{array}{c}\text { insinuación del } \\
\text { rostro, ausencia }\end{array}$ & $\begin{array}{c}\text { Ambigüedad del } \\
\text { gesto facial }\end{array}$ & Gesto violento \\
\hline \multirow{2}{*}{$\begin{array}{l}\text { Tratamiento } \\
\text { artístico plástico }\end{array}$} & \multicolumn{2}{|c|}{ Tratamiento del trazo } & \multicolumn{2}{|c|}{$\begin{array}{c}\text { Expresionismo } \\
\text { Caáacter de boceto } \\
\text { Pintura/dibujo }\end{array}$} \\
\cline { 2 - 3 } & \multicolumn{2}{|c|}{ Tratamiento del color } & \multicolumn{2}{|c|}{} \\
\hline
\end{tabular}

Fuente: Sandoval (2020).

Con relación al tratamiento plástico de la obra, si bien no podemos hablar de un manejo ambiguo del color o el trazo, sí cabe anotar que las decisiones plásticas de Caballero concomitaban con las intenciones representativas de lo figurativo. Acogiendo la propuesta de ValenciaHerrera (2015), la obra tendiente a la imagen necesaria desarrolló una estética mínima que privilegió, y se centró en la manifestación del cuerpo por sobre recursos plásticos como la precisión del trazo o el uso del color con fines referenciales. Evidentemente el color y el trazo estuvieron al servicio de la construcción y no de la representación, lo cual será otro aspecto que cooperará con la ambigüedad interpretativa, ya que, por ejemplo, un trazo fuera de una zona corporal se podrá identificar tanto como trazo de esbozo o como una sugerencia de movimiento o sombra. De cualquier forma, nos encontramos ante decisiones plásticas conscientes y controladas por el artista, y de acuerdo con esto, pareciera que, parte 
de ese control fue permitir que su huella personal en el trazo emergiera libremente siendo también evidencia de sus estados de ánimo (Canal Trece, 2018) ${ }^{13}$.

Figura 2. Luis Caballero. Sin título (1983)

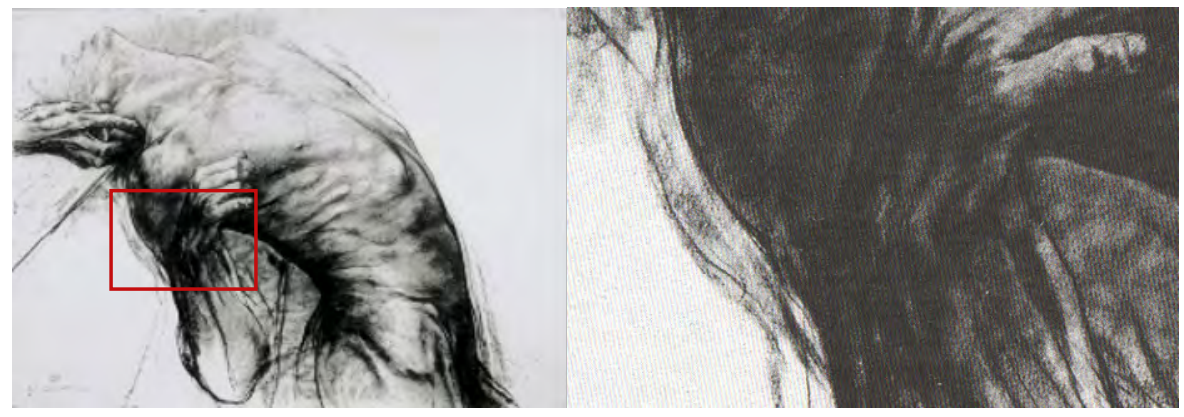

Nota. Carboncillo sobre papel. $70 \times 100 \mathrm{~cm}$. A la izquierda obra completa indicando la zona que se amplía a la derecha para la observación del detalle de los trazos. Fuente: Benjamín \& Caballero (2007).

Dentro de las anteriores descripciones acerca de los recursos pictóricos implementados por Caballero, emerge un aspecto relevante para reflexionar sobre la experiencia interpretativa que llevaría a un observador a identificar las emociones de los gestos, y es que, simultánea a la ambigüedad gestual, hay una ambigüedad espacial dada por el juego de fragmentación y omisión de información visual. El espectador se enfrenta a una información limitada pero suficiente para entrar en un juego de interpretación que habilitará emociones. El individuo asume los gestos que se podrían manifestar en las partes omitidas y las motivaciones que llevan a los cuerpos a adquirir las posturas que se manifiestan, las cuales son evidentemente incómodas y atípicas.

\section{La obra de Caballero como objeto estético}

Ya que la obra de Caballero induce al observador a un juego complejo de relacionamiento de información, tanto desde lo mostrado y sugerido como por lo omitido y, por tanto, supuesto, el enfoque de esta visita a la obra del pintor enfatizará en cómo es ese relacionamiento del espectador

$13 \mathrm{Al}$ respecto, se encuentran apreciaciones como la de Juan Camilo Sierra, secretario personal del pintor, quien comenta: "Por supuesto que toda la obra de Luis es profundamente autobiográfica, y si uno lo mira desde el principio hasta el final, recorre también esa sexualidad suya[...] ahí está, eso es él” (Canal 13, 2018). 
con los recursos pictóricos. Acorde con lo anterior se acoge el enfoque fenomenológico porque este, al privilegiar la relación sujeto-objeto, permite discriminar los niveles de consciencia y, por consiguiente, de relacionamiento, que el observador entabla con los recursos pictóricos anteriormente mencionados.

Sin el ánimo de hacer una extensa descripción del enfoque fenomenológico, brevemente se reseñará que este resalta el análisis de fenómenos que se establecen en la relación de consciencia que un sujeto entabla en la experiencia con un objeto (Husserl, 1962). Siendo más precisos en la experiencia perceptiva, la relación sujeto-objeto se da por la capacidad que ha de tener el sujeto, gracias a sus sentidos, de ser consciente del objeto en cuanto este es portador de características sensibles que se donan en conjunto al sujeto (Merleau-Ponty, 2000). Ya que la fenomenología propone "ir a las cosas mismas" ${ }^{14}$, Husserl dirige su mirada a cómo las cosas se presentan a la consciencia de manera inmediata, planteando que no podemos entender cómo se dan las cosas a la consciencia sin presuponer una relación con estas, es decir, el mundo pensado en su relación con la consciencia. El concepto de consciencia se toma de la teoría de la intencionalidad de Franz Brentano, quien define que "la consciencia es siempre consciencia de algo" (citado por Muralt, 1963, p. 41).

Ahora bien, la distinción de los objetos estéticos surge de las experiencias donde un sujeto puede tener consciencia de diferentes instancias cualitativas de un mismo objeto ya que dichas cualidades cumplen funciones particulares en la experiencia (Bundgaard, 2002). Acorde a la intencionalidad de la consciencia, siguiendo la línea husserliana, Bundgaard sostiene que la experiencia que un sujeto tiene de un objeto estético, como una pintura de arte figurativo, ha de posibilitar una consciencia de la distinción entre tres tipos de cualidades con relación a la función que cumplen en la experiencia: 1) el objeto material (bild), como un cuadro, un marco, un lienzo o pigmentos; 2) el objeto representado (bildsujet), por ejemplo, el motivo o aspecto figurativo, y 3)

\footnotetext{
14 "Ir a las cosas mismas" (Husserl, 1962) se refiere en fenomenología a dejar en suspensión subjetividades críticas que apelen a juicios u opiniones. Por ejemplo, para esta reflexión implica focalizar el fenómeno "pintura" con relación a un sujeto de la observación dejando en suspensión la información sobre quién es el pintor, el contexto de la obra e incluso entenderla como obra de arte. "Ir a las cosas mismas" también se refiere a alejarse de explicaciones teóricas o positivistas ya que estas no emergen en el acto experiencial.
} 
el objeto presentación de la representación (bildobjekt), manifestado en los colores, las formas, las manchas y los trazos.

Figura 3. Function of Qualities

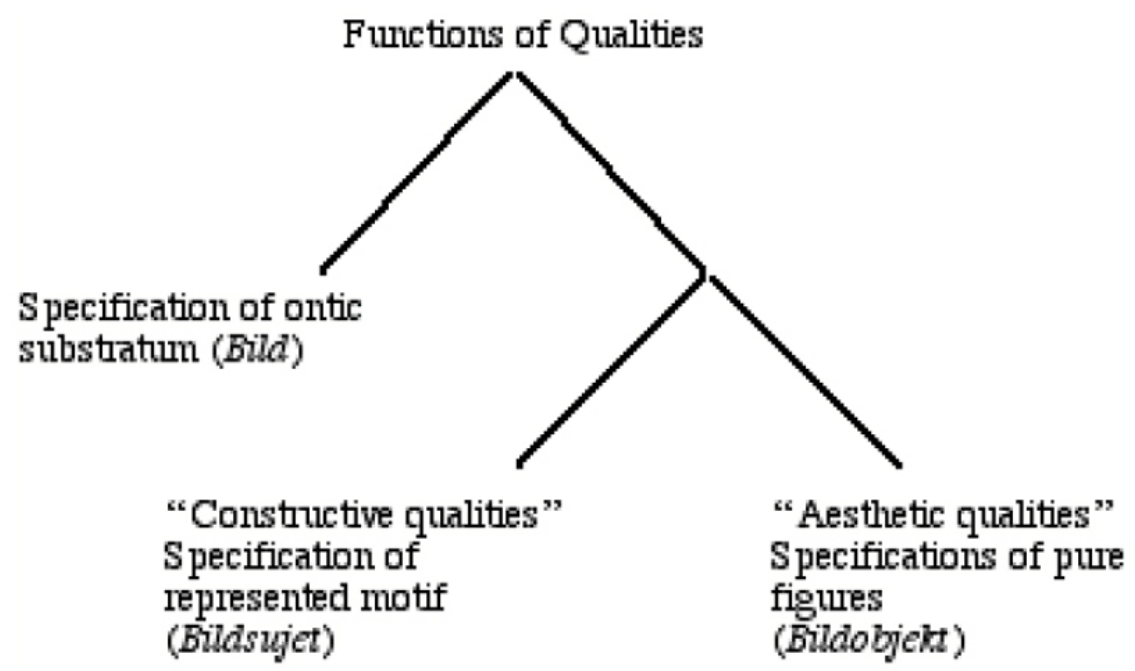

Fuente: Bundgaard (2002).

Según lo anterior, el sujeto podría ser consciente de estas tres instancias por separado, es decir, las experimenta como tres objetos distintos en una única experiencia estética. Uno de los fines con que Bundgaard acoge la propuesta de los objetos estéticos es la determinación de una secuencialidad en la dación de las cualidades, presuponiendo que, si bien la experiencia del objeto estético es gestáltica, la descripción fenomenológica da cuenta que el sujeto accede de manera secuencial a cada cualidad, por ejemplo, el relacionamiento inicial y básico ha de basarse en la determinación del bild, es decir, tener consciencia que se está ante un cuadro, una fotografía, una pantalla, etc. De no ser así, de llegar al reconocimiento de lo representado sin consciencia del objeto que lo contiene como representación, el sujeto ante la representación actuaría como si estuviera ante un objeto real. Un caso de la omisión del bild en una experiencia frente a un objeto estético se daba en las carreteras colombianas cuando hacia el 2012 se implementaron unas impresiones en cartón a escala real y a todo color de policías de tránsito con una señal de "pare". A cierta distancia era recurrente que los conductores identificaran las imágenes como policías reales ante lo cual efectivamente 
se reducía la velocidad y se asumían las posibles preocupaciones que implicaban la detención del policía. A medida que los autos se acercaban se hacía evidente el bild, es decir, emergían los aspectos materiales de la representación: la lámina de cartón, la impresión gráfica del policía, la ausencia de volumen, lo que a su vez conllevaba a un nuevo cambio de conducta como el no detenerse y la despreocupación de una posible amonestación. Cabe decir que el cuestionamiento de Bundgaard resalta la secuencialidad bildsujet-bildobjekt, ya que el planteamiento inicial de los objetos estéticos proponía que un sujeto reconocería primero lo representado en la imagen para en un posterior momento ser consciente de las huellas de presentación (Bundgaard, 2002) ${ }^{15}$. Bundgaard ejemplifica el caso contrario apoyándose en la obra Boats at sea de Joseph Mallord William Turner (1830-1845) ${ }^{16}$.

Ahora bien, el tratamiento artístico desarrollado por Caballero hace que en una misma obra se encuentren aspectos que se donan al espectador, como la representación, yuxtaponiéndose con zonas donde evidentemente prima la presentación, específicamente el trazo del artista. Para poder dar cuenta de aspectos como el que se acaba de mencionar, se comentará la siguiente obra ubicada dentro del periodo considerado como de búsqueda de la imagen necesaria ${ }^{17}$.

15 El caso con que se ejemplifica la secuencia bildsujet-bildobjekt es Le Jardin de l'artiste à Giverny de Monet, donde se suele llegar primero a los objetos representados, el jardín, con sus compontes, flores, árboles, hojas, antes de reparar que cada hoja es una pincelada.

16 Bundgaard argumenta que el espectador muy probablemente accede primero de manera consciente a las características estéticas de presentación: el color plano manifiesto en la superficie del lienzo con un leve contraste lumínico entre la mitad superior e inferior, y unas pinceladas rojas y negras en el centro. Posteriormente, gracias a la información dada por el título Boats at Sea, se da un nuevo sentido de carácter representacional en el cual la división del color del fondo se entiende como el horizonte y las pinceladas como dos barcos con sus respectivas sombras o reflejos en el agua (Sandoval, 2020, p. 59).

17 Para el desarrollo del trabajo de grado se seleccionó un corpus de análisis de dos obras pertenecientes al periodo de la estética mínima, propuesto por Valencia-Herrera (2015). El anexo 2 describe un esquema de disposición cronológica de las obras de Caballero, lo que permite hacer un ejercicio de visualización en conjunto de las obras recopiladas en (Benjamín \& Caballero, 2007). 
Figura 4. Luis Caballero. Sin título (1984)

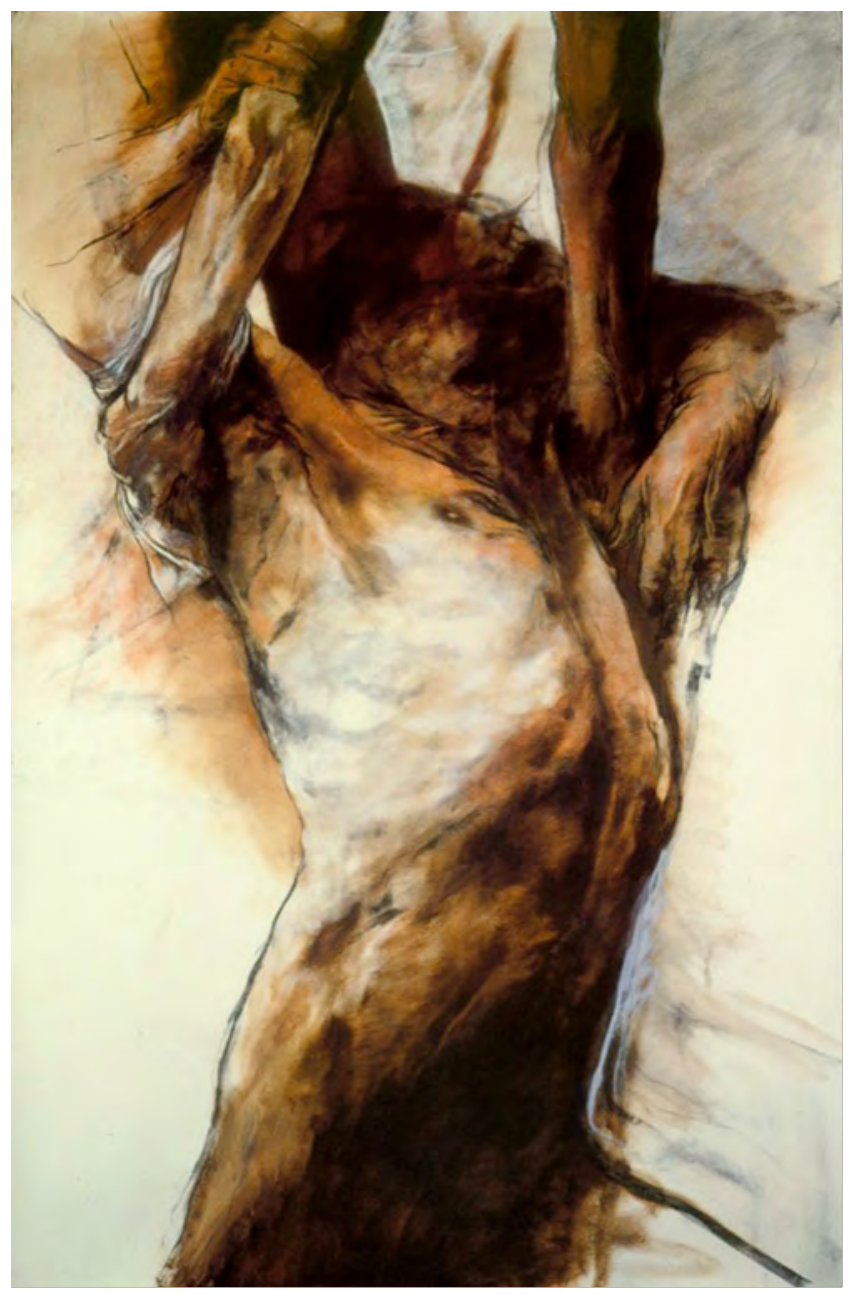

Nota. Óleo, sanguina y pastel sobre papel. 190 x 120 cm. Fuente: Benjamín \& Caballero (2007).

Es evidente que un observador accede con facilidad a las cualidades representativas de la obra, a un reconocimiento del cuerpo humano, fragmentado por los límites del bild que oculta las piernas, y por la no definición del rostro y los codos. Es precisamente esa no definición constante y selectiva de partes del cuerpo donde los aspectos de presentación coexisten con lo representado. En lugar de cabeza tenemos manchas, trazos desordenados que están más del lado de ser una huella plástica del artista, más que de ofrecer un rostro que manifieste un gesto. 
Esto, a su vez, difícilmente da cuenta del estado físico y emotivo de la persona representada: podría ser una cabeza destrozada, pero vemos que el brazo derecho del cuerpo se aferra a un segundo personaje también fragmentado, insinuado por sus extremidades, así que el personaje principal parece tener algún tipo de consciencia sobre la situación. Este juego de coexistencia entre cualidades de presentación y representación es el que habilita ambigüedades en la interpretación, y específicamente ambigüedades de la situación que envuelve a los personajes de la obra.

No obstante, el juego de presentación y representación de Caballero no solo se da en lo que muestra, sino también en sus omisiones, en las zonas del lienzo o papel que no interviene. Es recurrente que los cuerpos en esta etapa de su obra carezcan de escenario, como en el caso de la imagen citada. Al respecto de los fondos, Malagón-Kurska propone que "[...] el fondo blanco contribuye a la atención en la expresión del cuerpo" (2000, p. 25). Esta acotación sugiere que los espacios no intervenidos funcionan como una cualidad de presentación, ya que posibilitan un mayor contraste entre el entorno del dibujo y el cuerpo dibujado, lo cual hace que este último sobresalga. Sin embargo, el hecho de que los fondos carezcan de información que contextualice al cuerpo en un espacio representado de acción produce ambigüedad con relación a lo que los cuerpos experimentan o las motivaciones de estos. Recurrentemente los cuerpos de Caballero sobrepasan los límites del espacio sin acapararlo, lo cual permite que se manifieste un fondo que podría contextualizar la situación en la imagen. Al verse la presencia del otro individuo, es ambiguo el tipo de acción que se ejecuta sobre el cuerpo principal. La ausencia de información del espacio del cuerpo genera la incertidumbre acerca de su experiencia y situación, la cual se prolonga desde lo extra textual de la obra hasta que Caballero solía dejar "Sin título" sus pinturas.

\section{La representación en la obra frente a lo representado en la interpretación}

La propuesta de esta reflexión es que la fragmentación producida por la omisión de miembros del cuerpo en el dibujo, la ocultación de información por los límites del cuadro y la no definición de partes deja en evidencia que, si bien la propuesta fenomenológica de los objetos estéticos considera unas cualidades de representación, esta autoriza un espacio representado en la interpretación. La distinción entre la representación y lo representado es pertinente para identificar que la fragmentación es una suerte de presencia en la interpretación, esto es, mientras que 
la representación se da en el objeto estético, lo representado es la información de la interpretación para dar sentido a lo que se ve.

En la imagen que se ha citado como referencia, los límites del bild hacen que no haya representación de las piernas; no obstante, es factible que en las interpretaciones se suponga que el cuerpo representado las tiene. De ser así, ¿qué gesto han de tener? Si se consideran las posibles disposiciones de las piernas, estas podrían dar indicios de resistencia o cooperación frente a la acción del segundo personaje, pero al estar apenas sugeridas, en una leve posición de abducción, el espectador debería presuponer que las piernas poseen alguna posición que definiría su condición emocional. Por supuesto, no se pretende sugerir que un observador necesariamente piense en la posición de las piernas ante la imagen: sobre lo que se quiere reflexionar es precisamente el no cuestionamiento al respecto. Las piernas se dan como un hecho que ha sido ocultado por el límite del cuadro, y en cuanto piernas, la información que podrían proveer, pareciera, no se extraña para la identificación de lo que pasa en la imagen.

Caso contrario es el de los rostros, sean omitidos o distorsionados. Evidentemente serían mucho más explícitos para la expresión de los estados anímicos o de consciencia de su portador. Caballero desprovee al observador de cualquier información que especifique o sugiera una emoción. No obstante, los espectadores ante ellos les asignan emociones, a pesar de la limitada información, en términos gestuales, dada en la representación, a saber, el gesto del torso. Por esto se propone aquí que más allá de la asignación de emociones a los cuerpos, la reflexión pictórica del artista muestra la esencia del sentir, desligada de una convención social en la que se clasifican y definen las emociones. Evidentemente, Caballero estaba interesado en las experiencias místicas y eróticas corporales, pero algo que hace vigente su obra es que un observador desapercibido y alejado de estas convenciones, sin importar la universalidad de estas, encuentra en los cuerpos representados emoción pura, no intencionada ni clasificada. La obra de Caballero descubre para cada nuevo observador que la emoción es el cuerpo mismo.

\section{La experiencia de los cuerpos humanos reales y representados}

En Fenomenología de la percepción Merleau-Ponty (2000, p. 119) llama la atención acerca del papel del cuerpo como un objeto para la consciencia de un sujeto, es decir, se tiene la capacidad de ser consciente del propio cuerpo. El sujeto al ser poseedor de un cuerpo es un sujeto trascendental con capacidad de experimentar un mundo para-sí. La trascendencia del sujeto 
se relaciona con la búsqueda de la fenomenología por establecer unas condiciones de entendimiento del mundo alejadas de la subjetividad de los juicios y el positivismo. Husserl acogerá las categorías trascendentales de la sensibilidad kantiana, tiempo y espacio, como condiciones para la existencia y la experiencia del mundo (Husserl, 1962, pp. 32-33).

Los objetos del mundo se donan a la consciencia en diferentes condiciones y maneras, y sin importar estas, es necesario que haya un espacio y tiempo para que se manifiesten como fenómenos para un sujeto. El cuerpo propio, al ser también un objeto de la consciencia, existe dentro de las mismas condiciones del tiempo y el espacio; en estas condiciones trascendentales se relaciona con los otros objetos del mundo. Acorde con este relacionamiento Husserl reconoce que "[...] un objeto nunca se agota en una donación simple" (1962, p. 125), precisando que las perspectivas que se pueden tener de un objeto son inagotables, a pesar de que para la consciencia la dación del objeto es plena. Al respecto, Merleau-Ponty (2000) precisa que las perspectivas que un sujeto puede tener ante un objeto son infinitas, porque el sujeto, al poseer un cuerpo, se relaciona con los objetos gracias a las posibilidades que le permiten las condiciones trascendentales que el cuerpo y los objetos comparten. Si se supone que el sujeto trascendental se enfrenta ante un objeto cuerpo humano, las infinitas perspectivas perceptivas se darán en la posibilidad del alejarse o acercarse, rodear al otro cuerpo, tocarlo, agacharse para verlo desde abajo o subir a un objeto alto para observarlo desde arriba. Las variaciones de la iluminación develarán u ocultarán información visual, así como lo pueden hacer la presencia y ausencia de otros objetos (Sandoval, 2020, p. 74). En la experiencia de esas inagotables perspectivas que se puede tener con otros cuerpos, la consciencia, en cuanto consciencia de algo, tiene una idea, que, para sí, es plena acerca del cuerpo propio y del otro: el cuerpo posee volumen al ser tridimensional; tiene una disposición espacial sobre el horizonte, unas longitudes y unas partes. En esta última idea de complitud y esquema del cuerpo, producto de la experiencia de múltiples perspectivas, ante representaciones como las ofrecidas por Caballero, se puede interpretar que el cuerpo representado ha de estar completo (Sandoval, 2020, pp. 75-76).

Si a lo anterior le agregamos que un sujeto trascendental ante un objeto como el cuerpo humano no se encuentra con un objeto estático, sino, por el contrario, uno dinámico, que se mueve y, con este, sus partes, concluiremos que las experiencias posibles de los cuerpos, además de infinitas, son absolutamente ricas en variedad visual en comparación 
con un objeto estático. Los cuerpos se desplazan horizontalmente por el espacio y con un espectro de movilidad más restringido, en la verticalidad. La movilidad de las extremidades posibilita la contracción o estiramiento de cada parte por separado o del cuerpo en conjunto. La movilidad que puede darse a partir de los músculos del rostro permite una amplia gama de posibilidades en la manifestación de este. Estas posibilidades de disposición que puede manifestar un cuerpo es a lo que anteriormente nos hemos referido como gesto (Sandoval, 2020, p. 77).

En consecuencia, nos encontramos con que la obra de Caballero es una constante exploración de las infinitas maneras de manifestación del cuerpo. Su prolífica obra representa el afán por capturar de todas las formas posibles ese objeto del mundo que tanto le apasionó descifrar. Esa adoración obsesiva del cuerpo no se puede entender de una manera distinta a una filiación religiosa. Desde esta perspectiva, la devoción de Caballero es la que hace que los cuerpos se sacralicen, de tal razón que la observación constante de su obra hace que sus espectadores también sacralicen estos cuerpos en la contemplación y reflexión sobre las inagotables posibilidades del cuerpo que observan y que tiene resonancia en la experiencia del cuerpo propio. La gran obra de Caballero se hace grande en esta propagación, la cual va del gesto al sentir cuando en la interpretación se determina la emoción.

\section{El gesto corporal como representación de la emoción o la emoción misma}

Thus, how do we understand gestures? When we see a gesture, we do not turn inward in order to interpret its meaning through an analogy with our own experience: The gesture does not make me think of anger, it is the anger itself.

Merleau-Ponty, M.

Un aspecto que en este artículo ha de extrañar un observador de la obra de Caballero es que no se haya hecho mención alguna de las implicaciones del cuerpo desnudo. Como el foco de análisis es la experiencia del observador, quien evidentemente lo nota desde una primera observación, es de utilidad para esta reflexión abordar la desnudez en función de la emoción y no como aspecto estilístico o de género de la obra. Más pertinente aún es acoger la distinción entre desnudo y desnudez, que 
ofrece Clark Kenneth en su obra El desnudo: un estudio de la forma ideal (1956):

La desnudez corporal es aquella en la que nos encontramos desvestidos, despojados de nuestras ropas; por lo que dicha expresión entraña en cierta medida el embarazo que experimentamos la mayoría de nosotros en dicha situación. [...]. El desnudo [artístico] no comporta, en su uso culto ningún matiz incómodo. La imagen vaga que proyecta en nuestro espíritu no es la de un cuerpo encogido indefenso, sino de un cuerpo feliz o lleno de confianza: el cuerpo re-formado.

Evidentemente, Caballero opta por la desnudez en sus cuerpos despojándolos de orgullo. Son cuerpos que muestran una desnudez que los hace vulnerables; en cuanto emergen de los trazos de presentación, a materializarse en la representación, nacen vulnerables tanto ante los ojos de quienes observamos como un ambiente de la representación que no se puede precisar (Sandoval, 2020, p. 84). Los cuerpos son vulnerables por su desnudez y por un ambiente que oculta y devela una información: nos esconde los rostros y, por consiguiente, sus gestos, los cuales nos podría dar cierta certeza de sus emociones y condiciones de consciencia. Sin embargo, estos nos develan los gestos del torso para descifrar lo que experimentan, y esta disposición del gesto corporal muestra que, sea la motivación que sea, la emoción ha de ser extrema.

Precisando nuevamente que un sujeto-consciencia experimenta un mundo para sí, el primer objeto del mundo que ha de experimentar es el propio cuerpo, para, posteriormente, siendo un sujeto trascendental (consciencia-cuerpo) acceder a los demás objetos del mundo. La emoción puede surgir de algún tipo de relación introspectiva del sujeto o en la relación con su entorno, y, al manifestarse a través del cuerpo, pareciera que el sujeto es consciente de esta en la medida en que la experimenta en el cuerpo mismo: "Of course, 1 do not perform these gestures or emotions, but 1 catch on to their sense, 1 understand them in a nonthetic, non-reflective way" (Merleau-Ponty, citado por Landes, 2013, p. 89). En coherencia con el enfoque fenomenológico asumido para este análisis, se ha evitado determinar o clasificar cuáles son las emociones que experimentan los cuerpos de Caballero, con el ánimo de exaltar que estas son posibles en la experiencia corporal antes de pasar a una instancia reflexiva del sujeto. En esa misma vía, quizá un observador no necesariamente deba determinar una emoción en lo que ve, sino descubrir 
que el cuerpo que observa, a través de sus gestos, es emoción pura, irracional y primaria.

Acorde con esto, el tratamiento artístico de Caballero nos ofrece unos cuerpos extremadamente emocionados, alejándonos del gesto como un artefacto comunicativo y devolviéndole su carácter esencial: el gesto es la emoción misma. Observar estos cuerpos es una invitación a tomar consciencia del cuerpo propio con el cual nos hacemos hermanos con el otro, no en la similitud corporal del género, o la raza o la contextura, sino en la posibilidad del sentir.

\begin{abstract}
Ya sea que se trate de vestigios o del cuerpo de otro, la cuestión es saber cómo un objeto en el espacio puede llegar a ser la traza de un puente de una existencia. Cómo de manera inversa una intención, un pensamiento, un proyecto pueden separarse del sujeto personal y volverse visibles fuera de él en su cuerpo en el medio que se construye[...]. Ya lo hemos dicho, nunca se podrá comprender que el otro aparezca ante nosotros. Lo que hay ante nosotros es un objeto (Merleau-Ponty, 2015).
\end{abstract}

Parece que, para Merleau-Ponty, era evidente la conexión que tenemos con el otro, en términos de ser cuerpos además de compartir ciertas posibilidades temporales, espaciales e intersubjetivas. No es lo mismo interactuar con un florero que con otro sujeto, pues, con el otro, es posible un relacionamiento de consciencias que genera intersubjetividades. Ante el otro un sujeto puede salir de su aislamiento de consciencia a una intercomunicación con ese otro, volviéndose un ser en sociedad. En esta intersubjetividad juega un papel importante el lenguaje, pero, antes de este, ha de existir una intersubjetividad de los cuerpos que permite asumir el mundo, entenderlo y estructurarlo de una manera similar.

Esta visita a la obra de Caballero exalta que, sin importar las emociones asignadas a los cuerpos de Caballero, estas se interpretan como puras y extremas. Esa valoración emotiva desligada de una clasificación es suficiente para el proyecto de la imagen necesaria. Quizá el que los cuerpos se sacralicen ante los ojos de un observador es un aspecto ligado a la adoración dada en la fervorosa observación que mantuvo el artista sobre ese cuerpo que trasciende de un objeto a un sujeto en el sentir. Cada observación de Caballero es un acto de adoración, así como cada pincelada es una frase de sus plegarias, las cuales repetimos los observadores con cada nueva mirada a su obra. Estar ante la obra de Luis Caballero es reflexionar 
profundamente sobre la experiencia del cuerpo, y, por consecuencia, una experiencia visual de la existencia (Sandoval, 2020, p. 84).

Un cuerpo humano está aquí cuando, entre vidente y visible, entre quien toca y tocado, entre un ojo y el otro, entre la mano y la mano se hace una especie de entrecruzamiento, cuando se alumbra la chispa entre el que siente y lo sensible (Merleau-Ponty, 1986, p. 18).

Yo no sé si soy artista. Soy pintor. Y para mi ser pintor es tratar de dar forma visual a mis emociones y a mis sentimientos. Tratar constantemente y por todos los medios, de crear una imagen que se imponga por sí sola y que llegue a tener una existencia y una vida propia (Caballero \& Hernández, J. 1986, p. 18).

\section{CONCLUSIONES}

En el ocaso de su carrera Caballero decía "Hay que intentar hacer una gran obra. En general el arte contemporáneo peca por falta de ambición" (Caballero, 1990). Evidentemente no se refería a algo grande en términos cuantitativos, sino experienciales, es decir, a una gran obra que vaya más allá a una visualización, más allá de un encuentro fugaz en el museo. Hablaba, quizá, de una obra cuya experiencia trascendiera la representación para tener una relación íntima con el observador, cuestionándolo y confrontándolo. Caballero decidió enfrentar a cada observador con su naturaleza humana, y se podría asegurar que sus imágenes buscan expresar esas condiciones de existencia que definen al ser: su cuerpo, su sexualidad, sus emociones, sus relaciones con el otro. Ya en los 80 su búsqueda se centró en la individualidad del ser, y sin desconocer al otro, reconoce que la condición de existencia es el sentir, de tal razón sus cuerpos sienten las emociones más básicas y extremas, en las que emerge la consciencia de estar vivo.

Así como esta reflexión se valió de los postulados de la fenomenología para describir la experiencia visual ante la obra de Caballero, se podría decir que su obra, cuadro tras cuadro, fue un ejercicio fenomenológico alrededor de ese objeto llamado cuerpo: lo sustrajo de su contexto social, lo desnudó y lo despojó de un espacio físico definido. Observó al objeto en sus inagotables perspectivas y trató de capturarlas para entender más ese fenómeno del mundo. 
El artista cuestionó el espacio del cuerpo, que tenía una ambigüedad entre el espacio de la pintura y el espacio físico del cuerpo representado, dejando en evidencia esa dualidad de la existencia humana entre lo que se muestra y lo que se oculta, lo que se es y lo que se representa.

Caballero fragmentó al cuerpo sin tocarlo, sin diseccionarlo, porque a lo que le interesaba llegar no era a sus entrañas físicas, sino emocionales, cuestionando si las sensaciones son evidencias de la existencia o el sentir es la existencia en sí. Mientras fragmentaba el cuerpo mostró que la emoción, antes de usar al cuerpo como vehículo, era el cuerpo, se agotaba en sus gestos. El gesto corporal fue la manifestación de las inagotables perspectivas que observaba y capturaba del fenómeno, y en ese sentido la fragmentación quizá no era sobre los cuerpos, sino sobre sus gestos.

Al fragmentar los gestos, Caballero enfatizó en el gesto corporal, quizá porque el gesto facial es el que usualmente se nos presenta en la experiencia social, por lo que es más específico y, en algunos casos, menos genuino, ya que es manipulable. En cambio, el gesto corporal es más que emoción: es la esencia de todas las emociones. En el gesto corporal la emoción no es específica, es emoción pura y ambigua. Es así como precisamente nos referimos a las emociones, con ambigüedad. En la ambigüedad con que entendemos nuestras propias emociones es donde concordamos con la emoción del otro.

Un observador ante una obra de Caballero quizá no llegue a todas estas reflexiones que hizo el pintor, pero ahí están a disposición del que escudriñe en la imagen. Si las emociones propias nos son ambiguas al momento de definirlas, los gestos que nos muestra Caballero se acercan más a representarlas por la naturaleza de la ambigüedad. Preguntaba Conrad Detrez en el catálogo de la exposición de Caballero en Le Galería Jade, en Colmar, Francia, en 1980: “¿Esos jóvenes están vencidos por la muerte o por el placer? ¿Es la lucha? ¿Es el don? Encontrar el equilibrio entre esos extremos, buscar el nexo, comprender el gesto que les es común (el estertor del goce o de la agonía) eso es suficiente para cautivar a quien mire el cuadro" (Benjamín \& Caballero, 2007, p. 238). Es el gesto ambiguo, el que no se puede definir, el que hermana a los cuerpos de la obra de Luis Caballero con los cuerpos de quienes los observamos. 


\section{REFERENCIAS}

Arte y Cultura Alex Cuchilla (2018, 5 de diciembre). Luis Caballero entrevista y realizació n de mural, septiembre de 1990 [Archivo de video]. https://www. youtube.com/watch?v=1AsmRS9AqbE.

Bayón, D. (1990, mayo 17). Caballero al desnudo. La Prensa.

Benjamín, J. \& Caballero, A. (2007). Luis Caballero: homenaje. Villegas Editores.

Bungaraard, P. (2002). Presentation and representation in art. Ontic and gestaltic constraints. University of Aarhus.

Caballero, L. (1990.) Catálogo de exposición. Galería Garcés Velásquez.

Caballero, L. \& González B. (2014). ¡Pobre de mí, no soy sino un triste pintor! Cartas de Luis Caballero a Beatriz González. Universidad de Bogotá Jorge Tadeo Lozano.

Caballero, L. \& Hernández J. (1986). Me tocó ser así: conversaciones con José Hernández. Editorial La Rosa.

Canal Trece Colombia. (2018, 13 de octubre). Luis Caballero. https://www. youtube.com/watch?v=Ewg5IBxL3g4

Husserl, E. (1962). Ideas para una fenomenología pura y una filosofía fenomenológica. Fondo de Cultura Económica.

Kenneth, C. \& Torres. F (2008). El desnudo: un estudio de la forma ideal. Alianza Editorial.

Landes, D. (2013). The Merleau-Ponty Dictionary. Editorial.

Malagón-Kurska, M. (2000). La "imagen necesaria” en Luis Caballero [tesis de maestría]. Universidad Nacional de Colombia.

Malagón-Kurska, M. (2012). El deseo y el tormento secularizados en la obra de Luis Caballero. Banco de la República.

Maldonado, A. (2020, 27 de febrero) Luis Caballero en la colección del Banco de la República (Archivo multimedia). https://www.banrepcultural.org/luiscaballero/linea-de-tiempo.html

Merleau-Ponty, M. (1986). El Ojo y el espíritu. Paidós.

Merleau-Ponty, M. (2015). La prosa del mundo. Trotta.

Merleau-Ponty, M. (2000). Fenomenología de la percepción. Península.

Muralt, A. (1963). La idea de la fenomenología. El ejemplarismo husserliano. Centro de Estudios Filosóficos.

Ramírez, M. (2014). Cuerpo, fragmentación e ilusión de sintesis. Universidad Nacional de Colombia.

Rubiano, E. (2014). La imagen persistente: Catálogo de exposición Museo de la Imagen. Universidad de Bogotá Jorge Tadeo Lozano.

Sandoval, Ó. (2020). La experiencia interpretativa frente a la obra de Luis Caballero desde la fenomenología [tesis de maestría]. Universidad de Bogotá Jorge Tadeo Lozano.

Valencia-Herrera, M. (2015). Luis Caballero: entre el ánima erótica y la afección yacente. Universidad del Rosario. 